\author{
С.О. Коваленко, В.А. Турчина \\ Дніпровський національний університет імені Олеся Гончара
}

\title{
АНАЛІЗ ВПЛИВУ СТРУКТУРИ ГРАФІВ НА ОПТИМАЛЬНІСТЬ РОЗВ'ЯЗКУ ЗАДАЧ ПАРАЛЕЛЬНОГО УПОРЯДКУВАННЯ 3 ПЕРЕРИВАННЯМИ
}

В статті проводиться аналіз того, як може структура графа в задачі паралельного упорядкування впливати на оптимальність розв'язку залежно від того, чи дозволені у ній переривання, а також оцінюсться можливий виграш від використання переривань.

Ключові слова: теорія розкладів, задачі паралельного упорядкування, переривання.

\author{
Y.O. Kovalenko, V.A.Turchina \\ Oles Honchar Dnipro National University
}

\section{ANALYSIS OF THE GRAPH STRUCTURE INFLUENCE ON THE PARALLEL SEQUENCING PROBLEMS WITH INTERRUPTIONS SOLUTION OPTIMALITY}

The scheduling theory was originated at the beginning of the XX century and started to improve dramatically under the influence of production facilities increase around the world. The main aim was to optimize the time and resources consumption. However, later the scheduling theory problems became interesting to scientists as a separate subject of research as they could be applied to a wide variety of new problem classes.

The main subject of research is working process optimization. The limited amount of jobs and performers are presumed, also there could be different conditions involved. The solution of the scheduling theory problems implies finding the best jobs distribution among the set of performers in regard to the initial optimization criterion. The nature of jobs and the nature of performers usually do not affect the resolving process. A combination of jobs set and performers set forms the service system. This system could be multi-stage or singlestage depending on whether jobs are divided or not into the set of stages.

The class of parallel sequencing problems is a subclass of the scheduling theory problems. Initial conditions may include consistent restrictions on the jobs performing order, reflecting the technological process conditions. They are commonly represented as oriented graph optimization problems. Then each vertex conforms to a job and each arc conforms to one of the restrictions. The problems are also divided regarding whether interruptions are allowed or not. In a general case, when interruptions are forbidden, the graph is unweighted, but when interruptions are allowed each vertex has its own weight that shows how much time it would take to perform this job.

This article analyzes the question of how can the specific graph structure in the parallel sequencing problem affect the solution optimality depending on whether interrupts are allowed in it. The possible profit from using interruptions is also estimated.

Keywords: scheduling theory, parallel ordering problems, interruptions.

(C) Коваленко С.О., Турчина В.А., 2021 


\section{АНАЛИЗ ВЛИЯНИЯ СТРУКТУРЫ ГРАФОВ НА ОПТИМАЛЬНОСТЬ РЕШЕНИЯ В ЗАДАЧАХ ПАРАЛЛЕЛЬНОГО УПОРЯДОЧЕНИЯ С ПРЕРЫВАНИЯМИ}

В статье проводится анализ того, как может структура графа в задаче параллельного упорядочения влиять на оптимальность решения в зависимости от того, разрешены ли в ней прерывания, а также оценивается возможный выигрыш от использования прерываний.

Ключевые слова: теория расписаний, задачи параллельного упорядочения, прерывния.

Вступ. Теорія розкладів була започаткована на початку ХХ ст. зі стрімким зростанням виробничих потужностей у всьому світі і впродовж кількох наступних десятиліть активно розвивалася. Такий бурхливий розвиток був передусім зумовлений гострою потребою в раціональному використанні часу і ресурсів на виробництві. В подальшому ці задачі виявились цікавими і $з$ теоретичної точки зору, оскільки сприяли розробці нового математичного апарату для нових класів задач. Значний внесок в розвиток теорії зробили як вітчизняні, так і закордонні науковці, зокрема Танаєв В.С., Гордон В.С., Бурдюк В.Я., Шкурба В.В., Михалевич В.С., Гуляницький Л.Ф., Джонсон С.М., Конвей Р.В. та інші.

Основним об’єктом дослідження теорії розкладів є задачі оптимізації робочого процесу, коли для виконання певної скінченної множини робіт, скінченною множиною виконавців та певних умов щодо особливостей виконання цих робіт, визначається такий розподіл цих робіт між виконавцями, при якому оптимізується визначений умовами задачі критерій. При цьому характер робіт та природа виконавців суттєвого значення не мають. Роботою може виступати деталь, яку необхідно виготовити, виконання обчислення, передавання даних по мережі, перевезення вантажу тощо, так само і виконавцем може бути людина, станок, процесор, транспортний засіб і т. д.

В задачах теорії розкладів множина робіт та множина виконавців у сукупності утворюють обслуговуючу систему. Такі обслуговуючі системи поділяються на два види: одностадійні та багатостадійні. Різниця між цими видами полягає в тому, що в одностадійних системах будь-яка 3 робіт може бути повністю виконаною будь-яким 3 виконавців, в той час як багатостадійні системи передбачають розділення робіт на скінченні множини стадій таких, що кожну стадію роботи може виконувати лише поставлена їй у відповідність підмножина виконавців, причому лише один з них одночасно $[2,4]$.

Для одностадійних систем зазвичай визначений час виконання кожної роботи, окрім того можуть бути задані такі додаткові умови [5]:

- директивні терміни, коли бажано або необхідно, щоб виконання роботи було завершеним; 
- пріоритети у виконанні робіт;

- час надходження запиту на виконання роботи;

- інше.

В задачах паралельного упорядкування на множині робіт задається несуперечливі обмеження на порядок їх виконання, що відображають умови технологічного процесу. Вони зазвичай розглядаються як оптимізаційні задачі на орграфах, коли кожній роботі ставиться у відповідність вершина, а обмеження задаються у вигляді дуг [1]. Наразі найбільш дослідженими є такі дві задачі:

1) Задача 3 довільною кількістю робіт та виконавців, технологічні обмеження утворюють граф, який є орієнтованим вхідним деревом або лісом, необхідно мінімізувати час виконання робіт.

2) Задача $з$ довільною кількістю робіт та двома виконавцями, технологічні обмеження утворюють граф довільного вигляду, необхідно мінімізувати час виконання робіт.

Для них відомі точні алгоритми поліноміальної складності $[8,9,10]$.

Постановка задачі. Припускається, що задана деяка скінченна множина робіт

$$
A=\{1,2, \ldots, n\}
$$

та скінченна множина виконавців

$$
B=\{1,2, \ldots, m\} .
$$

Також задається час виконання кожної роботи кожним з виконавців

Якщо виконується

$$
t_{i j}>0, i \in A, 1 \leq j \leq m .
$$

$$
t_{i j}=\tau_{j} t_{i}, i=\overline{1, n}, j=\overline{1, m},
$$

то продуктивність $j$-ого виконавця при виконанні $i$-ої роботи складає $\frac{1}{\tau_{j}}$. Якщо при цьому $\tau_{j}=1$ для $j=\overline{1, m}$, то всі виконавці вважаються ідентичними [6]. Розглянемо саме такий випадок, тоді час виконання робіт задамо у вигляді

$$
T=\left\{t_{1}, t_{2}, \ldots, t_{n}\right\}, i=\overline{1, n} .
$$

Для моделювання технологічних обмежень на порядок виконання робіт на множині $A$ задається відношення часткового порядку і позначається символом « $\rightarrow$ » Таким чином для довільних $i, i^{\prime} \in A$ виконання роботи $i$ повинно завершитися до початку виконання роботи $i$ ' якщо $i \rightarrow i$ '. Задається орієнтований граф $G(V, U),|V|=n$ такий, що кожній роботі $i \epsilon A$ відповідає вершина $v_{i} \epsilon V$, а відношенню порядку відповідають дуги.

Наведемо деякі відомі означення [1].

Означення 1. Паралельним упорядкуванням $S$ вершин орграфів $\epsilon$ таке розміщення елементів множини $V$ на $n$ місцях, розташованих в лінію (допуска- 
ються порожні місця), коли кожен елемент розміщується лише на одному місці. Крім того, якщо із вершини $i$ йде дуга в вершину $j$, тобто $(i, j) \in U$, то вершина $i$ знаходиться в $S$ лівіше за вершину $j$.

Означення 2. Довжиною упорядкування $l(S)$ будемо називати кількість непорожніх місць в $S$.

Означення 3. Шириною упорядкування $h(S)$ будемо називати величину $\max _{1 \leq i \leq l}|S[i]|$.

В залежності від критерію оптимальності задачі паралельного упорядкування мають такі постановки.

Задача 1. За заданим орієнтованим графом $G$ та шириною паралельного упорядкування $h(S)$ треба знайти паралельне упорядкування мінімальної довжини, тобто $l(S) \rightarrow \min _{S}$.

Задача 2. За заданим орієнтованим графом $G$ та довжиною паралельного упорядкування $l(S)$ треба знайти паралельне упорядкування мінімальної ширини, тобто $h(S) \rightarrow \min _{S}$.

Вплив переривань на оптимальність. Задачі паралельного упорядкування поділяються на два типи в залежності від того, чи допускаються переривання при виконанні робіт.

Означення 4. Перериванням будемо називати випадки, коли виконавець починає виконання роботи, але призупиняє до іï повного завершення в певний момент часу, а потім в більш пізній момент часу виконання роботи продовжується або до наступного переривання, або до повного завершення.

У класичному варіанті, коли переривання не допускаються, для задач 1 та 2 час виконання кожної роботи приймається за 1. В такому випадку відповідний задачі граф $G \in$ незваженим. У випадку, коли переривання допустимі, кожній вершині ставиться у відповідність число, що дорівнює часу виконання даної роботи. Таким чином отримуємо зважений граф.

Постають питання, чи можна зменшити довжину упорядкування якщо дозволити переривання? Якщо так, то як на це впливає структура графа? Для цього введемо оцінку виграшу від використання переривань $W$ наступного вигляду:

$$
W=\left(1-\frac{l_{I}^{*}}{l^{*}}\right) \cdot 100 \%,
$$

де $l^{*}$ - оптимальна довжина упорядкування без переривань, $l_{\Pi}^{*}-$ оптимальна довжина упорядкування з перериваннями.

У [3] показано, що дозвіл переривань дійсно може зменшити довжину упорядкування, окрім того було доведено, що у випадку ізольованих вершин, коли $U=\varnothing$, переривання можуть давати суттєвий виграш. Для рисунків, що наведені нижче, в парах виду $(d, e)$, якими позначені вершини, $d-$ відповідає номеру вершини, а $e-$ відповідній вазі. 
Розглянемо приклади для паралельно-послідовних графів за означенням, наведеним в [6]. 3'ясуємо на прикладах, чи вплине на оптимальність розв'язків дозвіл переривань в такому випадку.

Приклад 1. Задано граф $G_{1}$ та ширина упорядкування $h=2$. Знайти мінімальну довжину упорядкування.

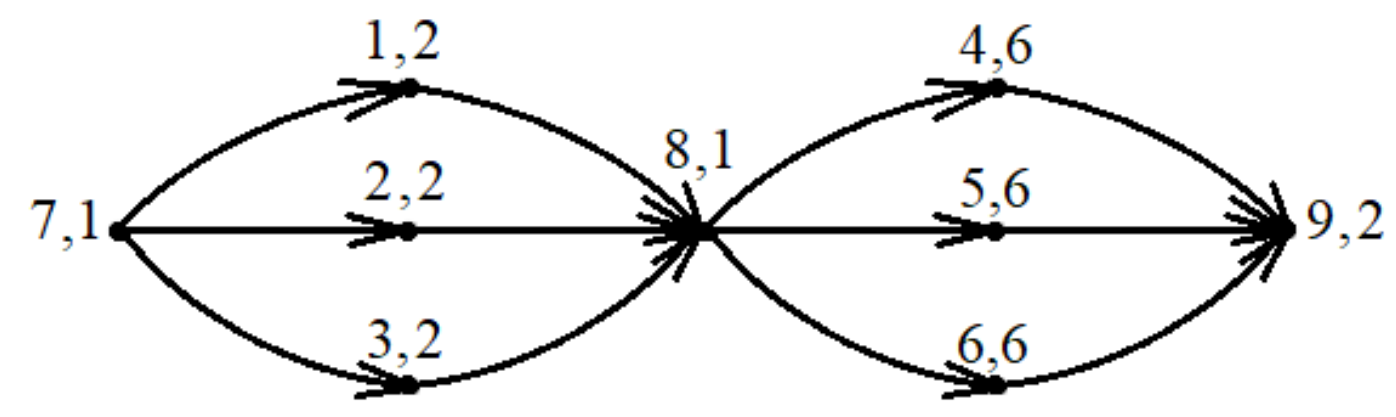

Рис. 1. Граф $G_{1}$

Побудуємо оптимальні розв'язки без переривань і з перериваннями для заданої ширини та порівняємо довжини упорядкувань.
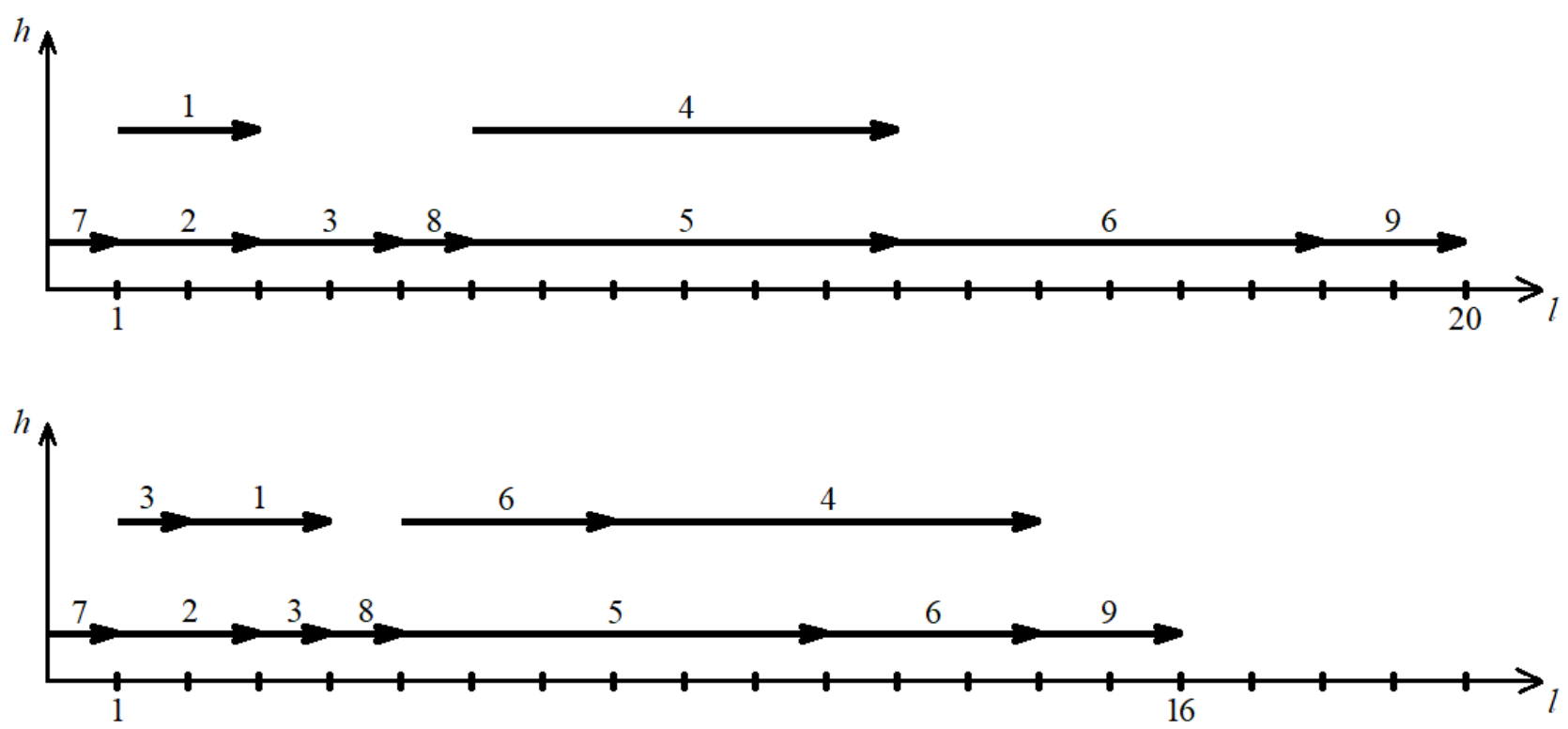

Рис. 2. Упорядкування графа $G_{1}$ без переривань та 3 перериваннями при $h=2$

Для заданого графа упорядкування з перериваннями дає виграш $W=20 \%$. 3 огляду на представлені упорядкування стає очевидно, що виграш при дозволі переривань виникає за рахунок кращого розподілу робіт між виконавцями, що зменшує сумарні простої в обслуговуючій системі.

Розглянемо узагальнений випадок для паралельно-послідовного графа 3 однією термінальною парою.

Приклад 2. Задано граф $G_{2}$ та ширина упорядкування $h=p$. Знайти мінімальну довжину упорядкування. 


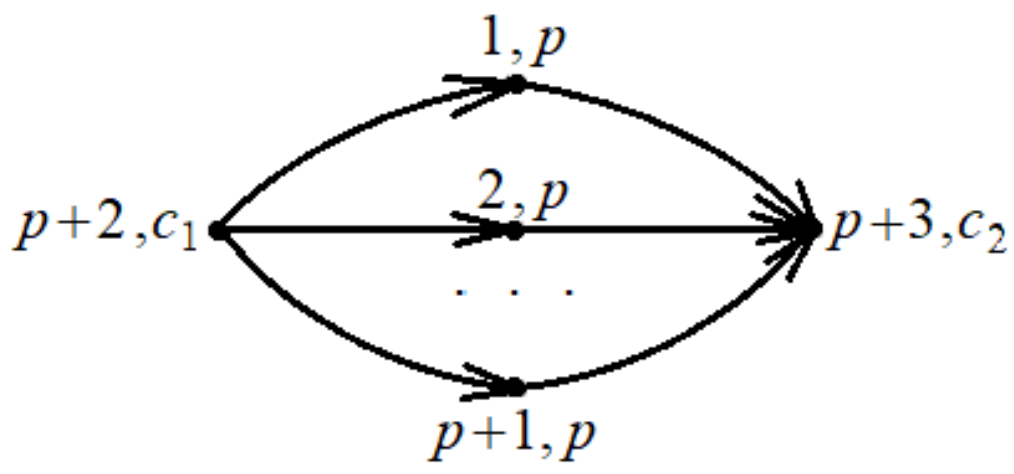

Рис. 3. Граф $G_{2}$
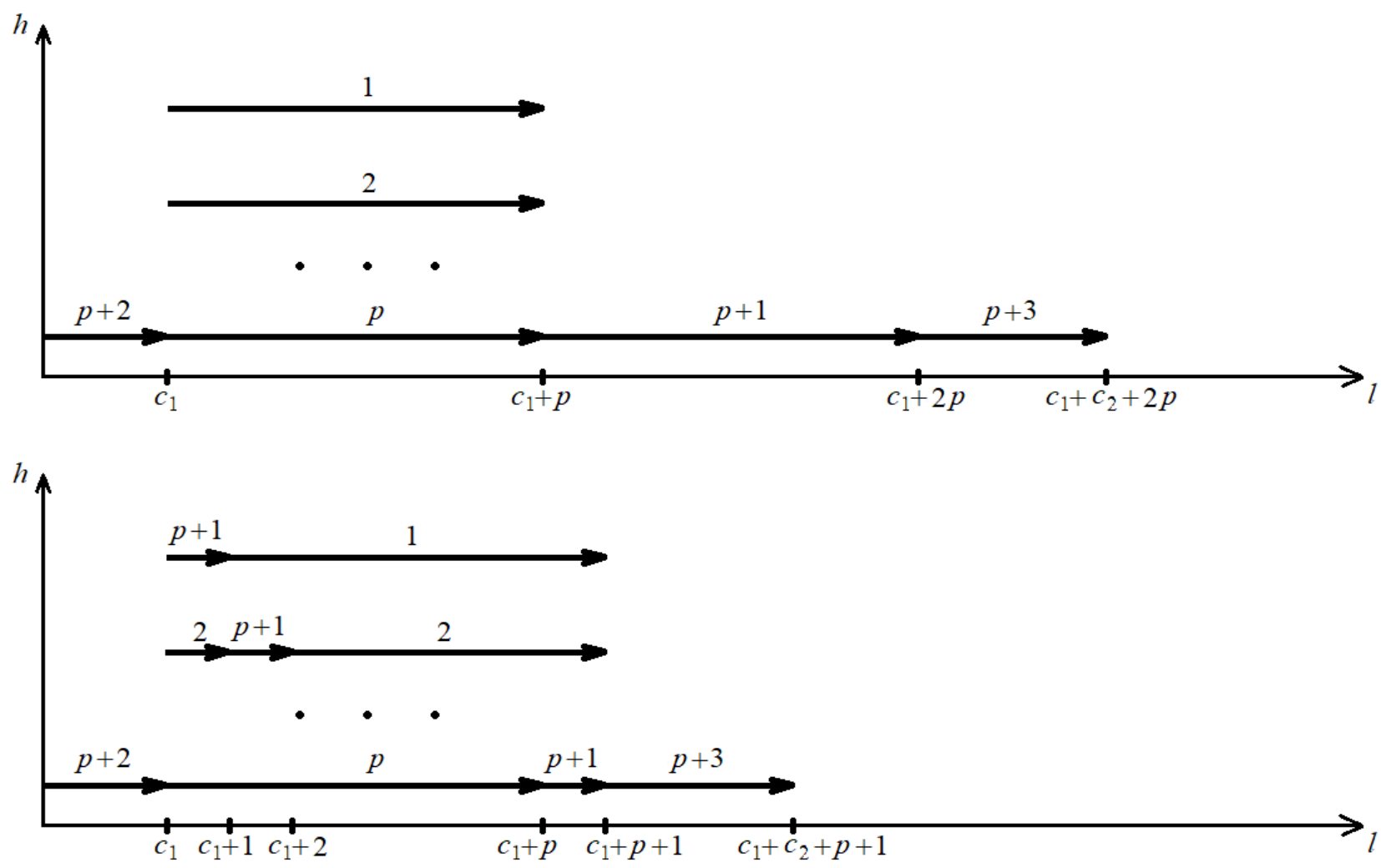

Рис. 4. Упорядкування графа $G_{2}$ без переривань та 3 перериваннями при $h=p$

Для зручності позначимо $C=c_{1}+c_{2}$ та матимемо виграш наступного вигляду:

$$
W=\left(1-\frac{C+p+1}{C+2 p}\right) \cdot 100 \% .
$$

Для його оцінки розглянемо два наступні випадки.

1) $C>p$, в цьому випадку виграш $W \rightarrow 0 \%$.

2) $p>>C$, в цьому випадку виграш $W \rightarrow 50 \%$.

Тепер наведемо приклад 3 довільною кількістю термінальних вершин.

Приклад 3. Задано граф $G_{3}$ та ширина упорядкування $h=p$. Знайти мінімальну довжину упорядкування. 

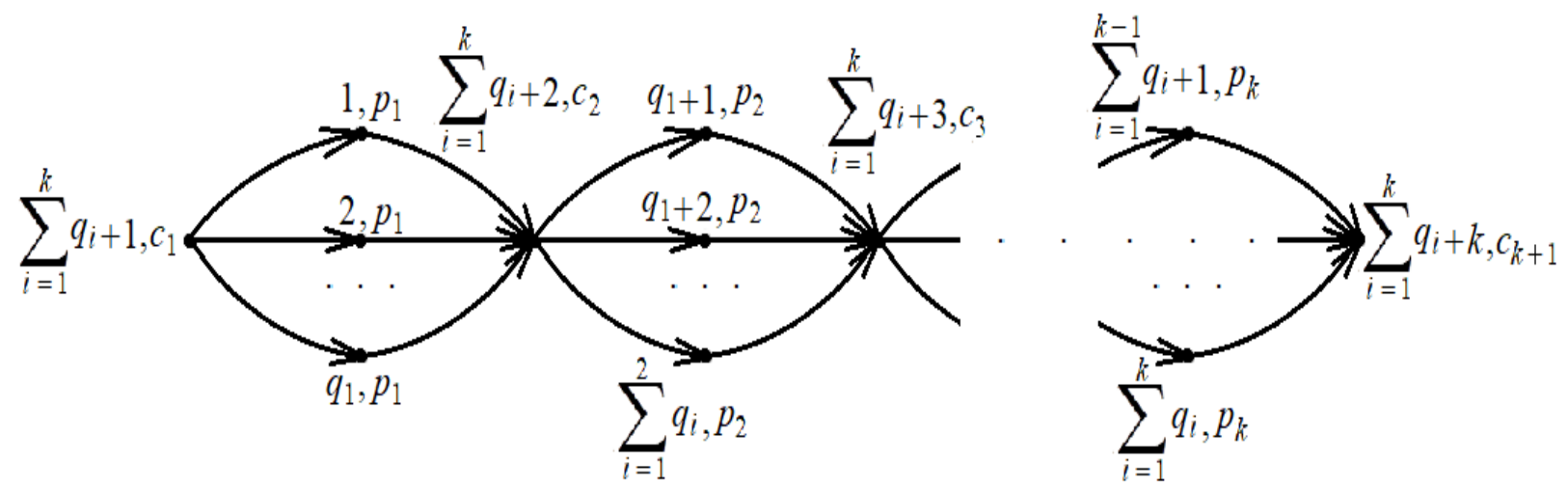

Рис. 5. Граф $G_{3}$

У випадку, коли всі $q_{i}=p+1, i=\overline{1, k}$ матимемо упорядкування без переривань та з перериваннями які показано на рис.6.
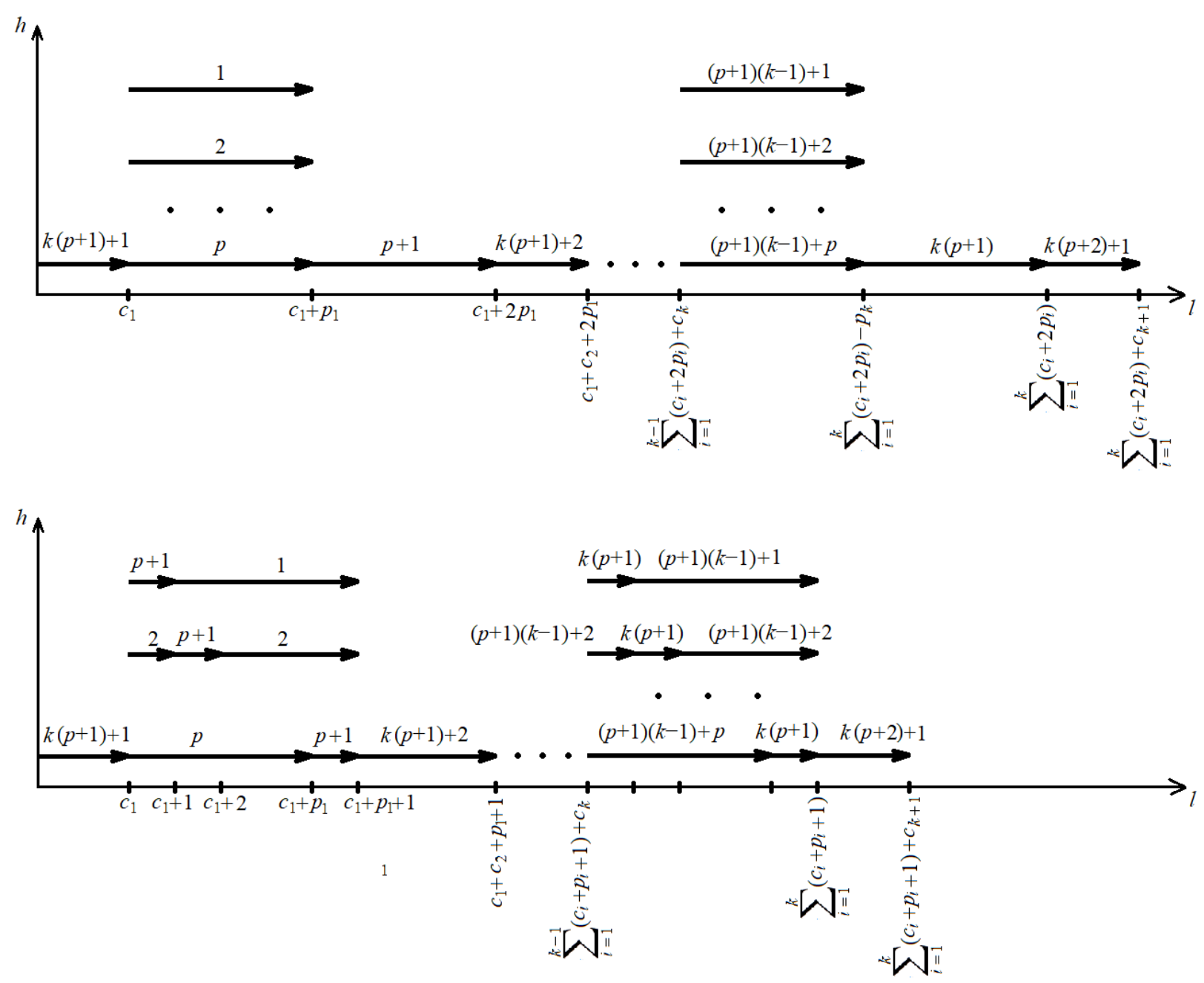

Рис. 6. Упорядкування графа $G_{3}$ без переривань та 3 перериваннями при $h=p$

Виграш від переривань будемо оцінювати аналогічно тому, як це робили для прикладу 2. Для зручності позначимо 


$$
C=\sum_{i=1}^{k+1} c_{i}
$$

Тоді виграш матиме вигляд:

$$
W=\left(1-\frac{\sum_{i=1}^{k}\left(p_{i}+1\right)+C}{\sum_{i=1}^{k} 2 p_{i}+C}\right) \cdot 100 \% .
$$

Як і в попередньому прикладі розглянемо 2 випадки:

1) $C>>\sum_{i=1}^{k} p_{i}$, в цьому випадку виграш $W \rightarrow 0 \%$.
2) $\sum_{i=1}^{k} p_{i}>C$, в цьому випадку виграш $W \rightarrow 50 \%$.

Висновки. Таким чином показано, що в задачах паралельного упорядкування вершин паралельно-послідовних графів дозвіл переривань може суттєво покращувати значення цільової функції навіть для ширини рівної 2.

\section{Бібліографічні посилання}

1. Бурдюк В.Я., Турчина В.А. Алгоритмы параллельного упорядочения: учебное пособие. Д.: ДГУ, 1985. 84 с.

2. Гордон В. С., Долгий А. Б. Задачи теории расписаний с заданным частичным порядком. Автомат. и телемех. 2010. Вып. 10. С.15-25.

3. Коваленко Є.О., Турчина В.А. Аналіз структури графів в задачах паралельного упорядкування з перериваннями. Кропивницький: ПП «Ексклюзив-Систем». 2021. С.86-90.

4. Конвей Р.В., Максвелл В.Л., Миллер Л.В. Теория рас писаний. М. 1975. 360 с.

5. Лазарев А.А., Гафаров Е.Р. Теория расписаний. Задачи и алгоритмы. Московский государственный университет им. М.В. Ломоносова (МГУ). 2011. 222 с.

6. Свами М., Тхуласираман К. Графы, сети и алгоритмы. М.: Мир, 1984. 455 с.

7. Танаев В.С., Гордон В.С., Шафранский Я.М. Теория рас писаний. М.: Наука. Главная редакция физико-математической литературы. 1984. 384 с.

8. Ху Т.С. Параллельное упорядочивание и проблемы линии сборки. Веб. «Кибернет. сб.». Вып. 4. М., Мир. 1967. С.41-56.

9. Fujii M., Kasami T., Ninomija K. Optimal sequencing of two equivalent processors. SIAM J. Appl. Math. 1969. 17. №4. P. 784-789.

10. Garey M.R., Johnson D.S. Scheduling tasks with nonuniform deadlines on two processors. J. Assoc. Comput. Mach. 1976. 23. №3. P.461-467.

Надійшла до редколегії 20.05. 2021. 